\title{
Quantitative Evaluation and Path Analysis of Factors Influencing the Cultivated-Layer Quality of Red Soil Sloping Farmland Based on the DPSIR Framework
}

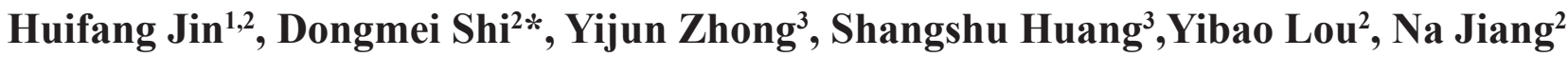 \\ ${ }^{1}$ College of Agriculture, Yangtze University, Jingzhou 434025, China \\ ${ }^{2}$ College of Resources and Environment, Southwest University, Chongqing 400715, China \\ ${ }^{3}$ Red Soil Institute of Jiangxi Province, Jinxian, Jiangxi,331717, China
}

Received: 28 March 2020

Accepted: 14 May 2020

\begin{abstract}
Quantitative evaluations of the cultivated-layer quality (CLQ)of sloping farmland are important for the effectively improving and rationally utilizing of the cultivated layers. Using a red soil watershed as the research object, we quantitatively analysed the relationship among factors influencing the CLQ using structural equation modeling based on the DPSIR framework (A framework for describing the interactions between society and environment developed by the European Environmental Agency) to describe the CLQ evolution process. We identified the key indicators of the driving factors (D) during cultivated-layer degradation and critical environmental pressure $(\mathrm{P})$ to construct a reasonable cultivatedlayer (RCL) by principal component analysis (PCA). We defined the main CLQ diagnostic indicator set to assess the CLQ by factor analysis and analysed the reasonable measures to improve the CLQ. The results show quantified direct or reverse effects among D, P, state performance (S), problem impacts (I) and response strategy $(\mathrm{R})$. The contribution rates of $\mathrm{D}$ and $\mathrm{P}$ were affected by the comprehensive effects of natural and human factors or human factors along. The CLQ diagnostic indicator set included 7 soil indicators and sub-soiling is the main adjusted measure for cultivated-layer recovery. These results could provide important technological paths for objectively understanding the causes drivers of the degradation and improving the CLQ for red soil sloping farmland.
\end{abstract}

Keywords: path analysis, cultivated-layer quality, influence factor, sloping farmland, DPSIR framework

*e-mail: shidm_1970@126.com 


\section{Introduction}

As a major foundation for agricultural production, red soil sloping farmland is an important arable land resource in the hilly regions of southern China. Abundant rainfall, dry-wet alternations and longterm blind cultivation by farmers have led to serious soil erosion in sloping farmlands, and the reduction of soil organic matter, thinning of cultivated layer, and deterioration of soil productivity. The CLQ plays an important role in maintaining crop productivity and environmental quality [1]. Currently, research on the CLQ of sloping farmland has mainly focused on soil quality, such as analysed the causal relationship of changes in soil quality [2], and predicted its variation trend [3], meanwhile, defined the CLQ based on the composition, structure, functional process, physical properties, chemical properties, timing and state of the soil system [4]. Researchers worldwide have also found that soil quality is affected by many factors $[5,6]$ and analysed the degree that different factors affect on soil quality. However, the interaction between various influencing factors and the influence of various factors have not been researched.

The DPSIR framework was formerly developed by OECD [7] in the PSR form, and used to highlight relationships between human activity and environmental degradation. This framework was based on the concept of causality: human activities exert pressures on the environment and change its quality and the quantity of natural resources [8]. The DPSIR framework is used to organize information based on the causal relationships between different indicators and factors and inherits the systematic and integrated characteristics of the PSR framework [9]; it effectively integrates the social economy, natural environment and human activities and combines their systematic and hierarchical characteristics; furthermore [3, 10], it is considered an orderly method for exploring causal relationships and widely used in ecological resource evaluation. $\mathrm{Lu}$ et al. [11] holistically evaluated the overall ecological effect of a polluted urban river during restoration based on the DPSIR model. Zhou et al. [12] assessed agricultural sustainable development and described processes and interactions in human-environmental systems of Jiangsu Province, China. Bae et al. [13] applied the concept of sustainability in the DPSIR framework to select all appropriate indicators of climate change impacts and quantified spatial vulnerability for sustainable water resources management. However, the causality relationship of different factors influencing CLQ evolution and the quantitative degree of influence of each factor have not been assessed by the DPSIR framework.

SEM is a statistical method that is commonly used to develop a causal understanding from observational data [14] and it can provide an overall motivation for evaluating causal network hypotheses [15], It has been used to gather insight into the drivers of ecological interactions and processes in soils [16], assess the relationships between organic carbon and soil properties [17], explore the transformations of phosphorus in tropical soils [18], establish the relationship-transferring chain of climate-crop-soil quality and quantify the interrelationships among these three factors and soil quality to guide agricultural production [19]. We argue that SEM is an extension of regression and path analysis that can be used to model multivariate relations and evaluate multivariate hypotheses; additionally, it is particularly to providing a statistical framework to achieve these objectives.

Taking a red soil small watershed as the research object, the DPSIR indicators were selected by the indicators that affected the CLQ in the early stage and the actual characteristics of sloping farmland. We constructed the DPSIR framework that affecting the variation in the CLQ and specifically divided the indicators into the five aspects of D, P, S, I and R. The paper aimed to (1) establish the relationshiptransferring chain that affects the CLQ using SEM with DPSIR framework, and empirically analyse the transformation of the CLQ; (2) quantitatively analyse the path relationships between factors influencing of the CLQ and identify the key D indicators for the cultivated-layer degradation and the key P indicators for the construction of RCL; and (3) specify the diagnostic indicator set of the CLQ. The results could provide an important parameter basis and technical approach for objectively understanding the causes of degradation, trend prediction, improved CLQ and RCL construction for red soil sloping farmland.

\section{Materials and Methods}

\section{Cultivated-Layer Quality Evaluation System Based on the DPSIR Framework}

Fig. 1 shows the DPSIR framework based on causality, which organizes information and related indicators and reflects a causal chain of the reasons, results, impacts, and regulatory measures of the cultivated-layer degradation of sloping farmland. The causal relationship reflected by the five factors of the DPSIR framework is a dynamic reflection mechanism. Under the influence of D, farmers increase their use of agricultural machinery to increase food production [20], which promotes changes in farming practices and leads to $\mathrm{P}$ in sloping farmland [21]. Agricultural machinery fieldwork will cause certain state (S) changes, such as soil compaction, which produces varying degrees of I [22]. These I factors include a reduction in the drought resistance of the cropland and the destruction of the soil structure [23]. The CLQ could be regulated in the agricultural production process by improving tillage methods, optimizing planting patterns and promoting soil and water conservation behaviors among farmers [24], which are referred to as the 


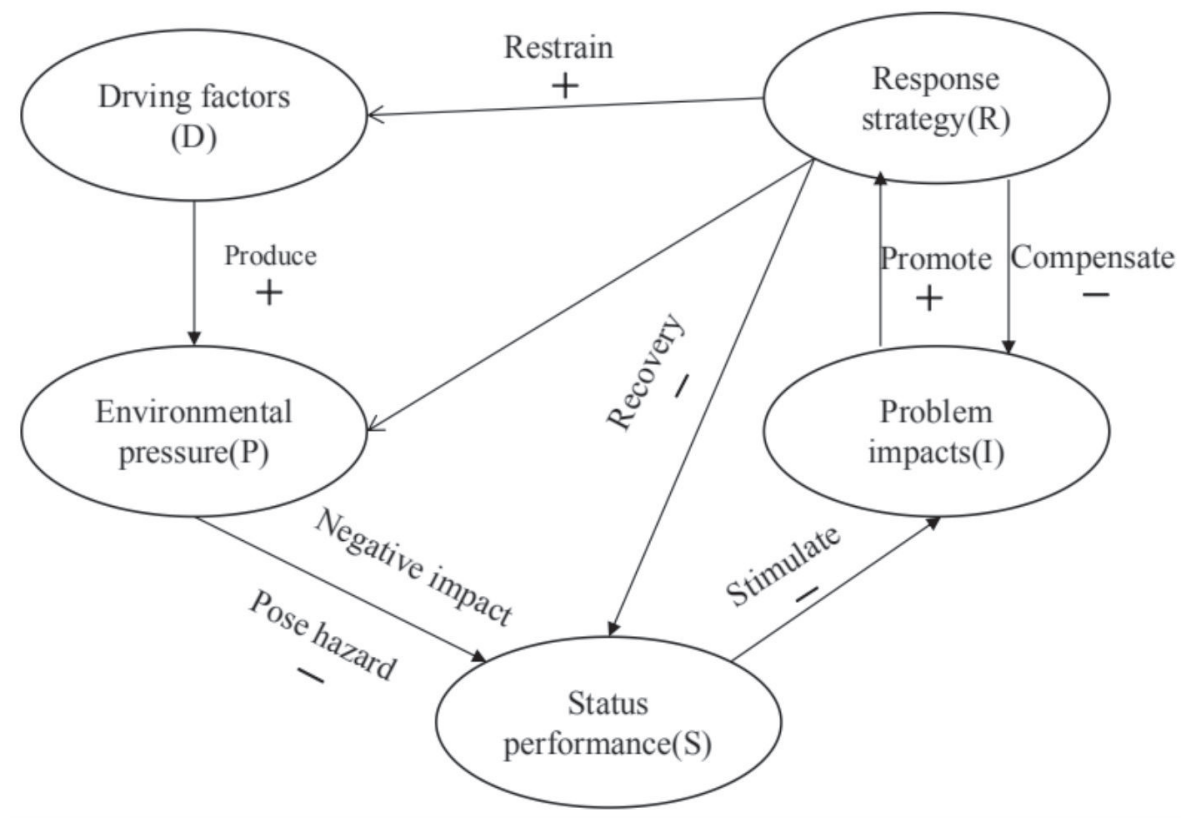

Fig 1. The theoretical framework of DPSIR.

response measures (R). The parameter Ds represents the fundamental power and potential incentives that cause cultivated-layer degradation, and they affect the CLQ and the environment of the sloping farmland. $\mathrm{D}$ causes $\mathrm{P}$ and subsequently triggers changes in the ecological environment and the cultivated-layer state. Such changes are generally negative and include the emergence and development of stratum degradation. Degradation of the cultivated layer and the environment will affect the CLQ and lead to additional issues. These factors have led to the adoption of a series of positive measures to restrain, improve or prevent the occurrence of CLQ problems [25].

Based on the DPSIR framework, this paper adopted a top-down approach to analysing the CLQ evaluation system by each layer. The feature layers were divided by different types of environmental elements (Table 1). Each criterion level contained different indicators. We collected the documented literature on CLQ [10, 25-29], and combined the CLQ characteristics of red soil sloping farmland $[30,31]$ and expert opinions of the research object to select the DPSIR indicators.

\section{Study Area}

The study area is located in the San he red soil small watershed in Jiangxi Province, China

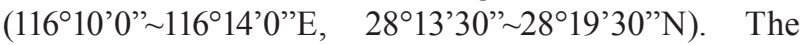
area is a typical red soil sloping farmland distributed over a region of $41.21 \mathrm{~km}^{2}$ and is characterized by a subtropical monsoon climate with an average annual rainfall of $1587 \mathrm{~mm}$; the range of annual evaporation is $1,100-1,200 \mathrm{~mm}$. The annual average temperature in this area ranges between 17.7 and $18.5^{\circ} \mathrm{C}$, The accumulated temperature of $\geq 10^{\circ} \mathrm{C}$ is $5,660^{\circ} \mathrm{C}$, and the average frost-free period is $282 \mathrm{~d}$. The landform characteristics are dominated by low hilly terrain. The slope ranges from $2^{\circ}$ to $35^{\circ}$. In general, the soil is acidic. The parent material of the soil is Quaternary red clay. The common planting systems include peanutcorn rotation, peanut-rape rotation, and soya bean-sweet potato rotation, and the cropping system is singlecropping once or double-cropping once.

\section{Sampling Point Setting}

A $3 \times 2 \times 3 \times 3$ sampling point setting method was used in the small watershed. In the upper, middle, and lower reaches of the small watershed, two areas with red soil sloping farmland were selected. Then, three typical slopes were selected in each area, and the sample sites were located on the upper, middle and lower slope positions. The angle and length of the slope were suitable in each location, and the crops were typical local crop types. All sites were owned by different farmers to ensure the representativeness of the plots, and 54 sample sites were identified in the small watershed.

\section{Soil Sample Collection, Tests and Questionnaire Survey}

Squares $1 \mathrm{~m} \times 1 \mathrm{~m}$ in size were placed in the central area of the sample sites. Soil samples were collected seperately at depths of $0-10$ and 10-20. At each site, approximately $1 \sim 2 \mathrm{~kg}$ of soil was collected for each soil layer and packed into rigid plastic boxes for transportation to the laboratory. The collected soil samples were dried naturally and screened to test the physical and chemical properties of the soil. The 


\begin{tabular}{|c|c|c|c|c|c|c|c|c|c|c|c|c|c|c|c|c|c|}
\hline & $\ddot{n}$ & 3 & 工 & 丰 & 丰 & L & 山 & 工 & 工 & \begin{tabular}{l|l}
3 & 3 \\
\end{tabular} & 山 & 山 & 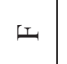 & 厌 & 山 & 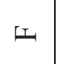 & 㝳 \\
\hline & 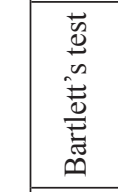 & \multicolumn{6}{|c|}{ 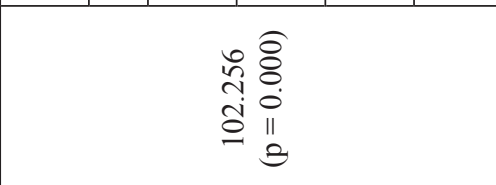 } & \multicolumn{5}{|c|}{ 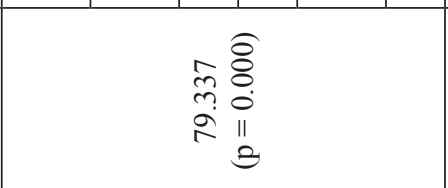 } & \multicolumn{5}{|c|}{ 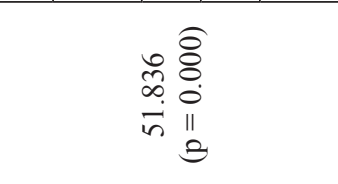 } \\
\hline & 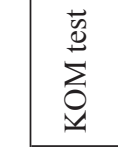 & \multicolumn{6}{|c|}{$\begin{array}{l}m \\
\infty \\
\infty \\
0\end{array}$} & \multicolumn{5}{|c|}{$\hat{a}$} & \multicolumn{5}{|c|}{\begin{tabular}{l}
\multirow{d}{0}{} \\
$\stackrel{0}{0}$
\end{tabular}} \\
\hline & 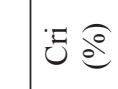 & $\underset{+}{\sigma}$ & $\begin{array}{l}\infty \\
\infty \\
\infty \\
\end{array}$ & $\underset{\infty}{\infty}$ & $\stackrel{\infty}{\infty}$ & $\stackrel{f}{\dot{r}}$ & $\stackrel{n}{n}$ & $\stackrel{\leftrightarrow}{\dot{f}}$ & $\vec{i}$ & \begin{tabular}{l|l}
$\stackrel{0}{:}$ & $\vec{i}$ \\
$\dot{m}$ & $\dot{m}$
\end{tabular} & $\stackrel{\infty}{\stackrel{m}{m}}$ & $\stackrel{8}{:}$ & $\begin{array}{l}\infty \\
\infty \\
i\end{array}$ & $\stackrel{\infty}{n}$ & $\stackrel{\hat{n}}{i}$ & $\stackrel{R}{i}$ & $\stackrel{+}{m}$ \\
\hline & $\ddot{U}$ & $\begin{array}{l}\infty \\
\infty \\
\infty \\
0\end{array}$ & $\begin{array}{l}\vec{\nabla} \\
\infty \\
0 \\
0\end{array}$ & $\begin{array}{l}\text { I } \\
\infty \\
0 \\
0\end{array}$ & $\stackrel{\vec{\infty}}{0}$ & $\begin{array}{l}t \\
\stackrel{0}{0} \\
0\end{array}$ & $\stackrel{0}{0}$ & $\begin{array}{l}\infty \\
\infty \\
\infty \\
0 \\
0\end{array}$ & $\begin{array}{l}\tilde{1} \\
\stackrel{\infty}{0} \\
0\end{array}$ & \begin{tabular}{l|l} 
& 0 \\
0 & 0 \\
0 & 0 \\
0 & 0 \\
0
\end{tabular} & $\begin{array}{l}\overrightarrow{0} \\
0\end{array}$ & $\begin{array}{l}n \\
0 \\
\infty \\
0 \\
0\end{array}$ & $\begin{array}{l}\text { ते } \\
\text { : } \\
\end{array}$ & 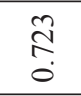 & \begin{tabular}{l|}
$\vec{\infty}$ \\
0 \\
0
\end{tabular} & $\begin{array}{l}n \\
\infty \\
0 \\
0\end{array}$ & $\begin{array}{l}\infty \\
\infty \\
\infty \\
0\end{array}$ \\
\hline & $\frac{\pi}{0}$ & $\bar{x}$ & $\tilde{x}$ & $\ddot{x}$ & $\dot{x}$ & $\ddot{x}$ & $\succsim$ & $\bar{x}$ & $\stackrel{\infty}{x}$ & 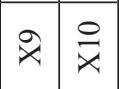 & $\overline{\bar{x}}$ & $\stackrel{2}{x}$ & $\stackrel{m}{x}$ & $\vec{x}$ & $\stackrel{n}{x}$ & \begin{tabular}{l}
\multirow{x}{*}{} \\
\end{tabular} & $\bar{x}$ \\
\hline & 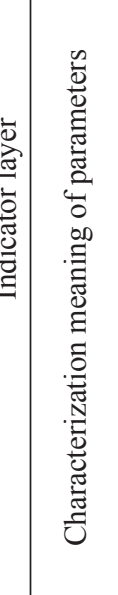 & 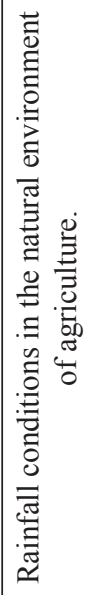 & 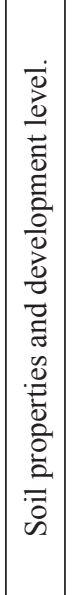 & 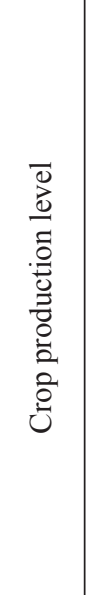 & 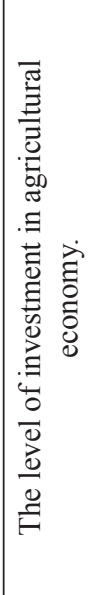 & 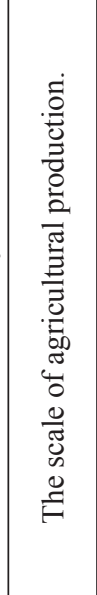 & 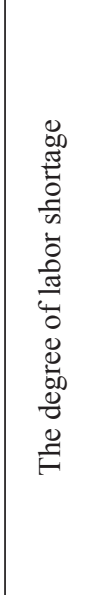 & 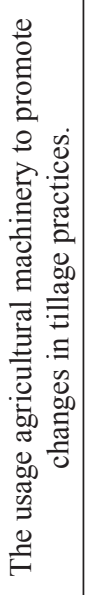 & 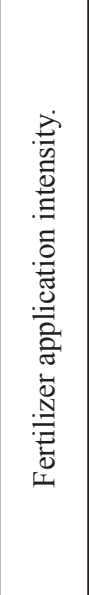 & 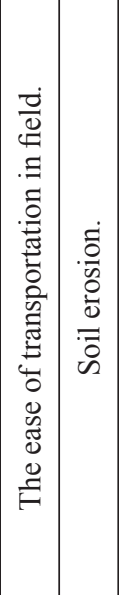 & 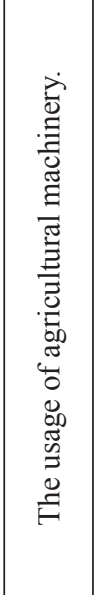 & 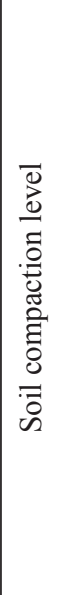 & 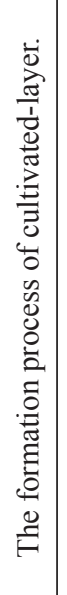 & 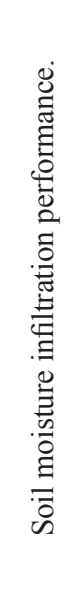 & 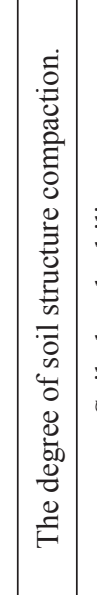 & 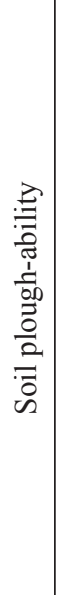 & 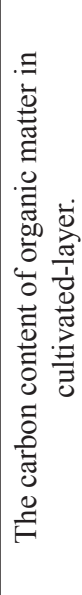 \\
\hline & 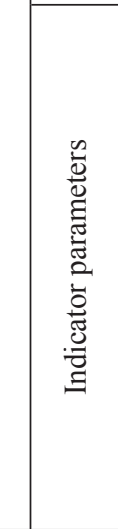 & 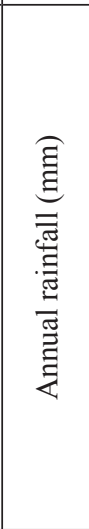 & 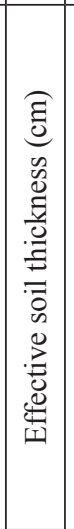 & 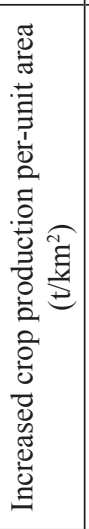 & 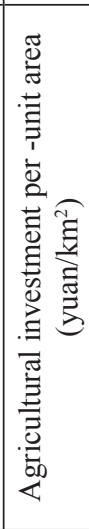 & 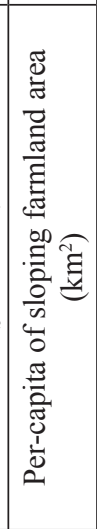 & 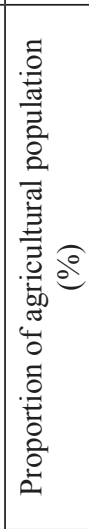 & 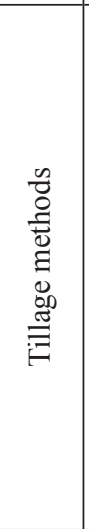 & 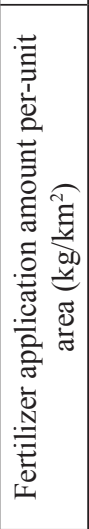 & 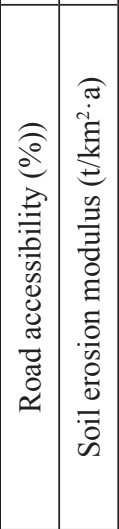 & 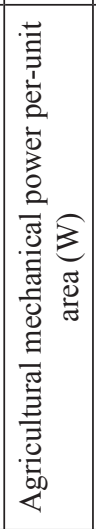 & 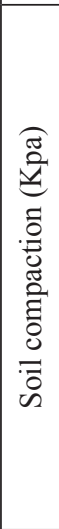 & 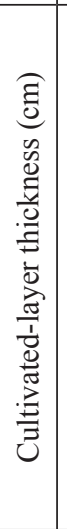 & 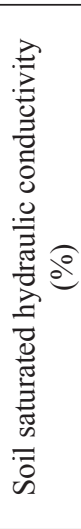 & 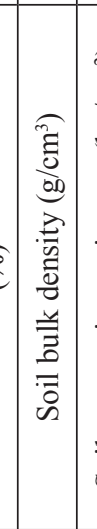 & 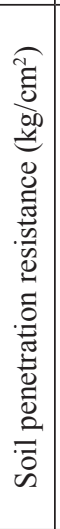 & 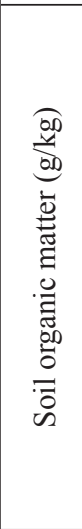 \\
\hline & 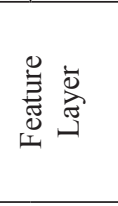 & 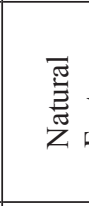 & & & 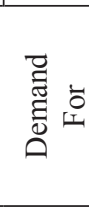 & 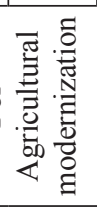 & & & 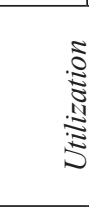 & 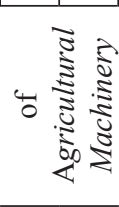 & & & & & 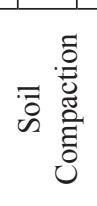 & & \\
\hline & 㺃 & & & & & & & & & 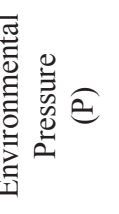 & & & & & 总 & & \\
\hline & 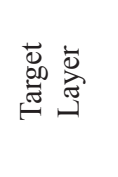 & & & & & & & 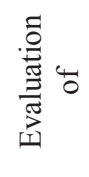 & : & 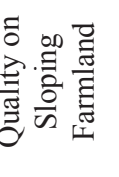 & & & & & & & \\
\hline
\end{tabular}




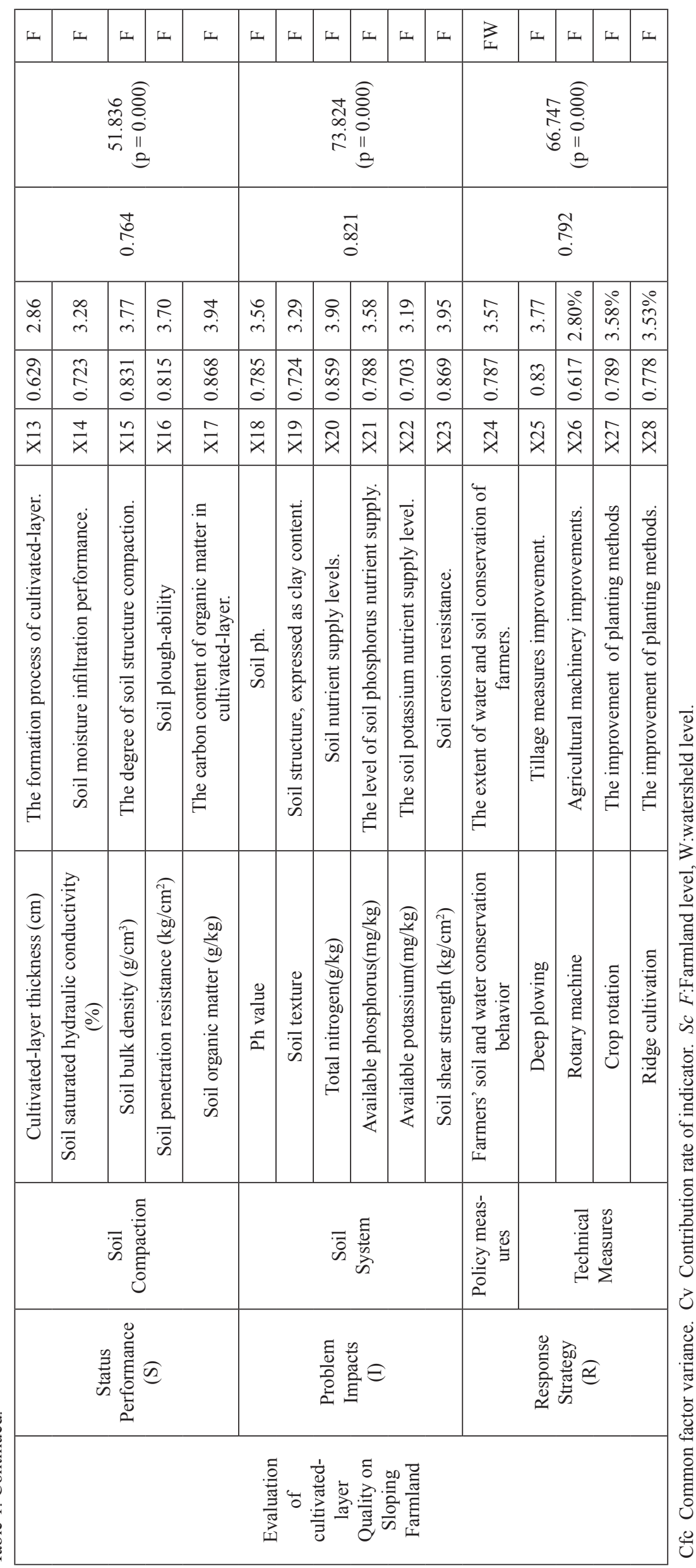


natural moisture content of the soil was measured via aluminum box testing, and the soil bulk density (X15) was determined by the cutting ring method by a tworing infiltration method to test the soil saturation hydraulic conductivity (X14). The soil compaction (X12), soil shear strength (X23) and soil penetration resistance (X16) were measured via a TJSD-750-11-type soil compaction metre, three-head shear metre and PTtype pocket penetration metre, respectively. The soil organic matter (X17) was measured via the potassium dichromate volumetric and outside heating method; the soil $\mathrm{pH}$ (X18) was measured via the soil-water ratio 1:1 electrode method; the soil texture (X19) was determined by the pipette method; the soil total nitrogen (X20) was measured via the semi-micro Kjeldahl method; the effective phosphorus (X21) was measured via the Olsen method; and the effective potassium (X22) was measured via $1 \mathrm{~mol} / \mathrm{L}$ NH4Ac extraction-flame spectrophotometry. The cultivated-layer thickness (X13) was the $90 \%$ root distribution depth excavated along the vertical section. The effective soil thickness (X2) was the depth from the surface to the mother rock, which was measured by a steel drill.

In addition, a questionnaire survey was formulated and the farmers who cultivated the 54 sampled plots were interviewed to obtain the corresponding indicator data, such as the human, social and economic indicators affecting the CLQ, and the indicators included the increased crop production per-unit area (X3), agricultural investment per-unit area (X4), per capita of sloping farmland area (X5), proportion of agricultural population (X6), tillage methods (X7), fertilizer application amount per-unit area (X8), road accessibility (X9), agricultural mechanical power per unit area (X11), farmers' soil and water conservation behaviour (X24), deep ploughing (X25), rotary machinery (X26), crop rotation (X27) and ridge cultivation (X28). Table 1 includes the results from the questionnaire. The annual rainfall (X1) and soil erosion modulus (X10) were watershed-scale indicators provided by the Red Soil Institute of Jiangxi Province, China.

\section{Data Analysis}

The quantitative data of the soil indicators of each sample were taken as the average value of the two soil layers, and the qualitative indicators were converted into quantitative data by the assignment method. The Z-score method was used to rescale the data such that the metrics of different units were comparable. AMOS and SPSS software were used for SEM,PCA and factor analysis, and Excel software was used for data processing and statistical analysis.

\section{PCA and Factor Analysis}

The PCA method was used to reduce the number of required indicator measurements, to select the most appropriate indicators from the list of indicators and to identify the main components that affected the results [1]. The steps is (1) calculating the correlation coefficient matrix of standardized data, (2) calculating the eigenvalues and eigenvectors of the correlation coefficient matrix, and (3) calculating the contribution rate and cumulative contribution rate of each principal component according to the eigenvalue order and then extracting the vector with an eigenvalue of $\geq 1$ to determine the number of principal components [32]. Finally, according to the load value of each principal component, the importance of the indicators can be determined to reduce dimension and reduce indicator redundancy. The key indicators of $\mathrm{D}$ and $\mathrm{P}$ were selected through this method. The factor load of the principal component was rotated by the maximum variance method. After performing a PCA analysis of the indicators and converting the square of the load to 0 or 1 , the factor score after rotation was obtained by factor analysis, which makes the loading matrix structure simple and significant of indicators [33]. The CLQ characteristic diagnosis of S and I were analyzed by this method. Factor scores of each treatment were calculated as follows:

$$
F_{i}=b_{i} X
$$

...where $F_{i}$ is the score of each common factor; $X$ is the different factor; and $b_{i}$ is the $i$-th column vector of the factor scoring coefficient matrix (Table 4).

$$
F_{c}=\sum_{i=1}^{m}\left(V_{i} / p\right) F_{i}
$$

where $V_{i} / P$ is the variance contribution rate after factor rotation $(\%)$ and $F_{i}$ is the score of each factor.

\section{Structural Equation Model}

As the path coefficient increases from one factor to another, the incidence increases. When the indicator load value of $\geq 0.5$, indicats that the data has good convergence validity. When the value of KMO of $\geq 0.5$, it is at a high level, and the significance level of Bartlett's test results with $\mathrm{p} \leq 0.005$, indicate that each indicator had a good ability to explain the factors, making this approach suitable for factor analysis by SEM.

\section{Results}

\section{Influence Path of Cultivated-Layer Quality Based on the DPSIR Framework}

Fig. 2 shows the results of an empirical analysis of the CLQ from the five aspects of D, P, S, I and R. D had a positive impact on $\mathrm{P}$, and a path coefficient of 0.96 . Therefore, when the $\mathrm{D}$ changed by 1 unit, the change 


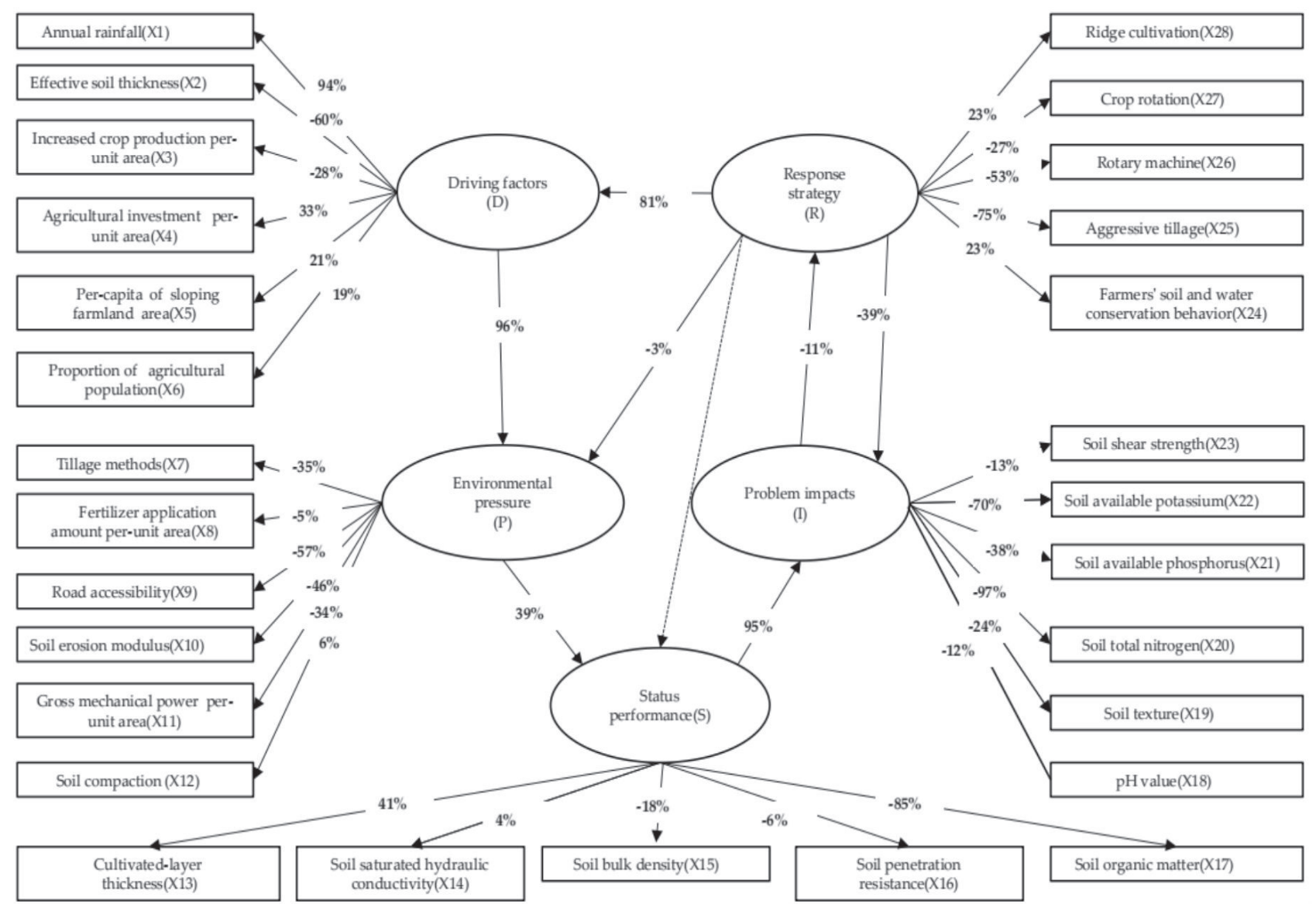

Fig 2. The path relationship of DPSIR of cultivated-layer quality.

rate of $\mathrm{P}$ was $96 \%$ in the same direction, indicating that $\mathrm{D}$ exerted obvious $\mathrm{P}$ on the CLQ. $\mathrm{P}$ had a positive effect on $\mathrm{S}$ and a path coefficient of 0.39 . Therefore, when $\mathrm{P}$ changed by 1 unit, the change rate of $\mathrm{S}$ was $39 \%$ in the same direction, which was different from the theoretical hypothesis (Fig. 1). The $\mathrm{S}$ factor for the CLQ had a positive effect on I, with a path coefficient of 0.95 . Thus, when $\mathrm{S}$ changed by 1 unit, the change rate of I was $0.95 \%$ in the same direction, which was different from the theoretical assumption (Fig. 1).

I had a negative impact on $\mathrm{R}$, and a path coefficient of -0.11 . Thus, when I changed by 1 unit, the change rate of $\mathrm{R}$ was $11 \%$ in the opposite direction. $\mathrm{R}$ had a clear positive effect on $\mathrm{D}$, with a path coefficient of 0.81 . Thus, when $\mathrm{R}$ changed by 1 unit, the change rate of $\mathrm{D}$ was $81 \%$ in the same direction, which increased D, such as the demand for agricultural modernization. The path coefficients of $\mathrm{R}$ on $\mathrm{I}$ and $\mathrm{R}$ on $\mathrm{P}$ were -0.39 and -0.03 , respectively. Thus, when $\mathrm{R}$ changed by 1 unit, the reverse rates of change of $\mathrm{P}$ and I were $39 \%$ and $3 \%$, respectively, which led to a reduction in $\mathrm{P}$ and $\mathrm{I}$. A clear influence path was not observed between $\mathrm{R}$ and $\mathrm{S}$, and it should be a focus of future research. As shown in the SEM results, a clear causal relationship was observed among D, P, S, I and $\mathrm{R}$, and this finding could be used for CLQ evaluations of red soil sloping farmland.

\section{Analysis of the Driving Factors (D) for Cultivated-Layer Degradation}

The PAC method was used to analyse the D underlying the cultivated-layer degradation. As shown in Table 2, the contribution rate of $\mathrm{PC} 1 \sim \mathrm{PC} 3$ was greater

Table 2. Principal component analysis of driving factors (D).

\begin{tabular}{|c|c|c|c|c|}
\hline \multirow{2}{*}{$\begin{array}{c}\text { Code } \\
\text { of Indicators }\end{array}$} & \multirow{2}{*}{ Group } & \multicolumn{3}{|c|}{ Principal components (PC) } \\
\cline { 2 - 5 } & 1 & 0.883 & 0.093 & -0.322 \\
\hline X1 & 1 & 0.82 & 0.14 & 0.13 \\
\hline X2 & 1 & 0.712 & 0.472 & -0.23 \\
\hline X3 & 2 & -0.58 & 0.723 & -0.242 \\
\hline X5 & 2 & -0.65 & 0.632 & -0.196 \\
\hline X6 & 3 & 0.658 & 0.452 & -0.554 \\
\hline X4 & 3.15 & 1.378 & 1.04 \\
\hline $\begin{array}{c}\text { Eigenvalues of PC } \\
\text { principal components }\end{array}$ & 52.508 & 22.965 & 10.67 \\
\hline $\begin{array}{c}\text { Variance contribution rate of } \\
\text { PC (\%) }\end{array}$ & 52.508 & 75.472 & 86.15 \\
\hline $\begin{array}{c}\text { The cumulative contribution } \\
\text { rate of PC (\%) }\end{array}$ & & & PC3 \\
\hline
\end{tabular}


Table 3. Principal component analysis of environmental pressure (P).

\begin{tabular}{|c|c|c|c|c|}
\hline \multirow{2}{*}{$\begin{array}{c}\text { Code } \\
\text { of indicators }\end{array}$} & \multirow{2}{*}{ Group } & \multicolumn{3}{|c|}{ The principal components } \\
\cline { 3 - 5 } & 1 & 0.762 & 0.235 & -0.297 \\
\hline X10 & 1 & 0.618 & 0.479 & 0.441 \\
\hline X12 & 1 & -0.515 & 0.471 & 0.346 \\
\hline X7 & 2 & 0.721 & 0.819 & 0.561 \\
\hline X9 & 3 & 0.566 & 0.516 & 0.674 \\
\hline X11 & 3 & 0.233 & -0.555 & 0.572 \\
\hline X8 & 1 & 1.725 & 1.13 & 1.089 \\
\hline Eigenvalues of PC & 33.745 & 23.839 & 23.153 \\
\hline $\begin{array}{c}\text { Variance contribution rate of } \\
\text { PC }\end{array}$ & 33.745 & 57.584 & 80.737 \\
\hline \multicolumn{2}{|c|}{$\begin{array}{r}\text { The cumulative contribution } \\
\text { rate of PC }\end{array}$} & &
\end{tabular}

than $10 \%$, and the cumulative contribution rate of these three principal components reached $86.15 \%$; thus, they could provide the greatest information regarding $\mathrm{D}$.

The D indicators X1(0.883), X2(0.820), X3(0.712), X4(0.658), X5(-0.580), and X6(-0.650) showed greater loads on PC1 (absolute load value $\geq 0.5$, the same as below), respectively. These factors included both natural and human indicators and thus could be regarded as comprehensive effects of natural and human factors. X5(0.723) and X6(0.632) accounted for a greater load on PC2; these indicators were all human indicators and could be considered influenced by human factors. X4 (-0.554)displayed a high absolute load value on $\mathrm{PC} 3$, which could be regarded as the effect of artificial factors. The contribution rate of the comprehensive effects of natural and human factors was $52.508 \%$, and the contribution rate of human factors was $33.94 \%$ without an absolute natural factor. These findings indicated that the intensity of the interactions between human and natural factors was relatively high with human factors playing a major role. X1(0.883), $\mathrm{X} 2(0.820), \mathrm{X} 3(0.712)$, and X4(0.723) all showed large load values, and their absolute load values were greater than 0.7. These indicators were the key driving force indicators affecting cultivated-layer degradation.

\section{Analysis of the Environmental Pressure (P) for RCL Construction}

$\mathrm{P}$ is directly applied on the sloping farmland after the action of $\mathrm{D}$ and has an important influence on the CLQ. The contribution rates of $\mathrm{PC} 1 \sim \mathrm{PC} 3$ were more than $10 \%$ according to the PCA, and their cumulative contribution rate reached $80.74 \%$. Thus, these components can provide most of the information on the factors underlying the $\mathrm{P}$ for the construction of RCL (Table 3).

The $\mathrm{P}$ indicators $\mathrm{X} 8(0.690), \mathrm{X} 9(0.721), \mathrm{X} 10(0.762)$, $\mathrm{X} 11(0.566)$ and $\mathrm{X} 12(0.618)$ showed greater load values on the $\mathrm{PC1}$, and included both natural and human indicators, thus, they could be regarded as the comprehensive effects of natural and human factors. X7(0.819) showed a larger load value on PC2; X11(0.674) had a relatively large load on PC3. Therefore, the dominant factors for these two indicators were human factors. The information contributed by the three principal components was $39.1 \%, 18.86 \%$, and $14.26 \%$, respectively, and their contribution ability gradually decreased. The contribution rate of the combination of natural factors and human activities reached $39.1 \%$, and the rate of human factors was $33.12 \%$; and an absolute

Table 4. Factor loading of cultivated-layer quality indicators ( $\mathrm{S}$ and I) after factor rotation.

\begin{tabular}{|c|c|c|c|c|}
\hline Code of indicators & $\begin{array}{c}\text { Production performance } \\
(\mathrm{F} 1)\end{array}$ & $\begin{array}{c}\text { Anti-erosion } \\
\text { capacity(F2) }\end{array}$ & $\begin{array}{c}\text { Tilth charactiristic } \\
(\mathrm{F} 3)\end{array}$ & $\begin{array}{c}\text { Acidification degree } \\
(\mathrm{F} 4)\end{array}$ \\
\hline X13 & -0.454 & -0.289 & 0.447 & 0.379 \\
\hline X14 & 0.145 & -0.257 & 0.521 & 0.263 \\
\hline X15 & 0.04 & 0.858 & -0.04 & -0.012 \\
\hline X16 & -0.323 & 0.67 & -0.142 & 0.134 \\
\hline X17 & 0.9 & -0.124 & 0.005 & -0.909 \\
\hline X18 & -0.201 & -0.097 & 0.064 & 0.203 \\
\hline X19 & -0.103 & -0.07 & -0.822 & 0.108 \\
\hline X20 & 0.874 & -0.2 & 0.19 & -0.006 \\
\hline X21 & 0.437 & -0.086 & 0.534 & 0.082 \\
\hline X22 & 0.77 & 0.023 & 0.236 & 0.121 \\
\hline X23 & -0.048 & 0.89 & -0.041 & 11.2 \\
\hline
\end{tabular}


Table 5. Single factor score and comprehensive score of cultivated-layer quality at different slope positions.

\begin{tabular}{|c|c|c|c|c|c|c|c|c|c|c|}
\hline \multirow{2}{*}{ Slope position } & \multicolumn{2}{|c|}{$\mathrm{F} 1$} & \multicolumn{2}{|c|}{$\mathrm{F} 2$} & \multicolumn{2}{|c|}{ F3 } & \multicolumn{2}{|c|}{$\mathrm{F} 4$} & \multicolumn{2}{|c|}{$\mathrm{F}_{\mathrm{c}}$} \\
\hline & Score & Rank & Score & Rank & Score & Rank & Score & Rank & Score & Rank \\
\hline Upper & -0.037 & 3 & 0.028 & 2 & -0.014 & 3 & 0.018 & 1 & 0.005 & 2 \\
\hline Middle & -0.03 & 2 & -0.106 & 3 & 0.006 & 2 & 0.005 & 2 & -0.126 & 3 \\
\hline Lower & 0.067 & 1 & 0.079 & 1 & 0.008 & 1 & -0.023 & 3 & 0.131 & 1 \\
\hline
\end{tabular}

natural factor effect was not observed. These findings indicated that the intensity of the comprehensive effects of human factors and natural factors was relatively high, with human factors accounting for the greatest impact from the increased use of agricultural machinery. The tillage method, soil erosion modulus and road accessibility showed high load values of $0.819,0.762$ and 0.721 , respectively, and represented the key $\mathrm{P}$ indicators affecting the CLQ of red soil sloping farmland.

\section{Analysis of Cultivated-Layer Quality (S and I)}

The CLQ indicates the ability to maintain soil productivity and environmental quality , and promote crop growth in the soil ecosystem [25]. We analysed the data of all indicators of S and I that reflected the characteristics of CLQ to accurately diagnose the main component characteristics The variance contribution rates of $\mathrm{F} 1 \sim \mathrm{F} 4$ were $30.3 \%, 18.21 \%, 11.2 \%$, and $9.8 \%$, and the cumulative variance contribution rate was $70 \%$. These four common factors could reflect most of the information in the CLQ. The load matrix of the first 4 common factors was rotated by the variance maxima, and the factor load after rotation was obtained (Table 4).

The load values of X17(0.9), X20(0.874), and $\mathrm{X} 22(0.77)$ on $\mathrm{F} 1$ were greater (absolute values $\geq 0.75$, the same as below) after factor rotation. These comprehensive factors reflected the productivity of the cultivated layer, and greater values corresponded to a stronger production performance of the cultivated layer. $\mathrm{X} 15(0.858)$ and X23(0.89) showed relatively greater load values of F2. These factors reflected the anti-erosion capacity of the cultivated layer, and greater values corresponded to a stronger anti-erosion capacity of the cultivated layer. X19 (clay content, -0.822) had a more prominent load value of F3. This factor reflected the tilth characteristics, and the negative soil texture value indicated that the tillage performance was relatively poor. The load value of the $\mathrm{pH}$ of F4 was -0.909 , which represented a prominent value, and indicated that soil acidification is the main obstacle. The four main factors that characterizing the CLQ were production performance, anti-erosion capacity, tilth characteristics and the degree of soil acidification .

The characteristics of CLQ varied significantly among the different slope positions. Table 5 shows the score of F1 ordered as the upper slope $(0.067)>$ middle slope (-0.03)>upper slope (-0.037). The anti-erosion capacity (F2) was lower slope (0.079)>upper slope $(0.028)>$ middle slope $(-0.106)$. The F3 score reflecting the tilth characteristic was ordered as follows: lower slope $(0.008)>$ upper slope $(0.006)>$ middle slope $(-0.014)$. Thus, the lower slope had the most concentrated area of sloping farmland. The average score values of F4 for the upper slope, middle slope, and lower slope were $0.018,0.005$ and -0.023 , respectively. The comprehensive factor score was ordered as follows: lower slope (0.131)>, upper slope (0.005)>middle slope (-0.126); indicating that the CLQ of the lower slope is more suitable for crop growth than other slope positions.

\section{Response Strategy (R) of Cultivated-Layer Quality}

Farmer participation in soil and water conservation was $31.4 \%$, which was mainly related to the low grain yield and low farmer awareness of water and soil conservation. Agricultural input and farmer subsidies have been increased by the government's policy and monetary compensation to promote the participation and awareness of farmers in soil and water conservation. The usage of deep tillage was $81.4 \%$, and it can improve the soil micro-environment, Moreover, the depth of soil disturbance exceeded the depth involved in conventional tillage, resulting in lower soil bulk density [3] and increased porosity [10], thereby overcoming the limitation of the plough bottom layer on water efficiency [34], increasing the soil

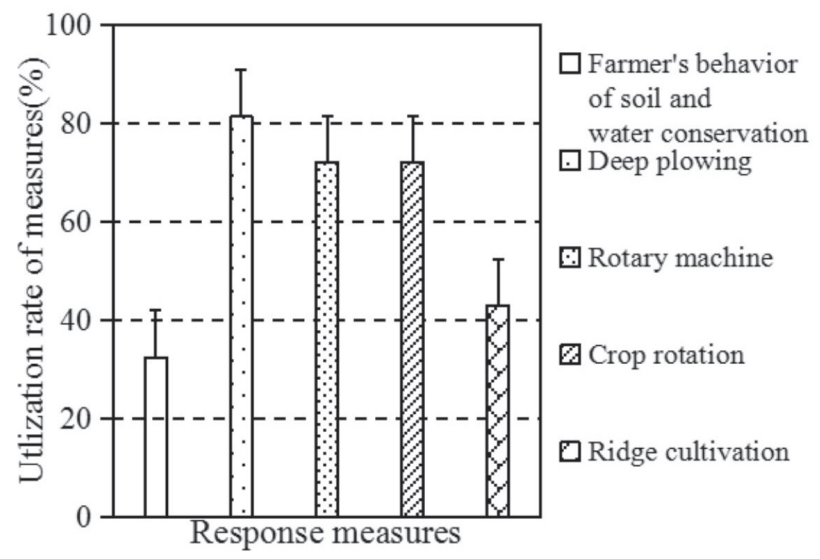

Fig 3. Utilization rate of adjustment measures for cultivatedlayer quality. 
water infiltration, and improving the soil water storage capacity [35]. The utilization rate of rotary tillers was $72 \%$, and the use of agricultural machinery can greatly improve labour productivity. The implementation rate of crop rotation measures was $72.2 \%$, which could effectively regulate soil moisture. The implementation rate of ridge farming was slightly lower, $46.2 \%$, and the current serious ageing of the rural labour force and low labour efficiency were the main reasons for the low implementation rate of this measure.

\section{Discussion}

\section{Influence Path of Cultivated-Layer Quality of Sloping Farmland}

Sloping farmland is a sensitive area of the ecological environment and shows serious soil and water loss [36], and the cultivated layer is the shallow layer, which disturbed by tools used to plant crops [25]. Reforming the CLQ is an important premise for improving soil productivity, and also significantly affected by social, economic, and natural factors and human activities, which play increasingly important roles in the degradation or improvement of the CLQ [37]. The cultivated-layer soil ecosystem is a complex system among nature, ecology, social economy and human activities. The interaction process between various factors in the system is quite complex, and the DPSIR framework can simplify this complex process [38]. A comprehensive analysis of the D-P-S-I-R, and affecting CLQ evolution can clarify the process of the various factors affecting the soil ecosystem of the cultivatedlayer and the causal relationships among them.

The research results showed clear causal relationships among $\mathrm{D}, \mathrm{P}, \mathrm{S}, \mathrm{I}$ and $\mathrm{R}$ (Fig. 3). D had a significant positive effect on $\mathrm{P}$. The migrant nature of the young labour force leads to a decrease in the rural labour force, and the ageing trend of the rural labour force is obvious [38, 39]. Increases in government inputs in agriculture have promoted an increase in the agricultural machinery utilization [40] and the construction of rural roads to that end. Combined with the comprehensive effect of rainfall runoff and soil properties, these changes cause serious soil erosion and soil compactness, which leads to increased pressure on the CLQ and accelerates the soil degradation of the cultivated layer. $\mathrm{P}$ had a positive effect on $\mathrm{S}$ at $39 \%$, which differed from the theoretical hypothesis (Fig. 2), but was consistent with the research results of Zhao et al. [41]. Soil acidification [42], viscous heavy accumulation [43] and poor nutrient supply [43, 44] were major obstacles to the CLQ of red soil sloping farmland. Recently, the guidance of national policies and improvements in farmers' knowledge levels have promoted rational tillage and fertilization methods of sloping farmland [45]. As soil maturation continues, soil erosion and soil acidification decrease, which positively improves the CLQ. In addition, the negative relationship between $\mathrm{P}$ and certain characterization indicators also explains the difference between the influence coefficient and the theoretical assumptions. $\mathrm{S}$ has a positive impact on $\mathrm{I}$ and a path coefficient of $95 \%$. This finding indicated that unreasonable fertilization and tillage measures will accelerate the soil degradation and nutrient loss of sloping farmland $[45,46]$. I had a negative influence on $\mathrm{R}$, and when the CLQ was in a better S and I state, society's interest in improving the CLQ of sloping farmland decreased. $\mathrm{R}$ had a relatively lower negative impact on $\mathrm{I}$ and $\mathrm{P}$. The positive agricultural measures could clearly improve the CLQ and alleviate the cultivated-layer degradation, which was consistent with previous research results [47]. The path relationship between $\mathrm{R}$ and $\mathrm{S}$ could be a focus of future research.

\section{Factors and Adjustment Measures of Cultivated-Layer Quality}

The cultivated-layer degradation of sloping farmland represents a reverse-succession process of the soil and ecosystem, and natural and human factors are the two driving forces [48]. The natural factors mainly include rainfall and soil type, which are the intrinsic causes underlying the cultivated-layer degradation [49], while human activities often accelerate the cultivated-layer degradation [50]. The increased use of agricultural machinery has promoted changes in tillage methods [51], from unreasonable tillage practices (steep tillage, sloping tillage, shortening the tillage cycle of the round trip, etc.) to mechanical tillage and cross-slope cultivation etc [52] which could reduce soil erosion and soil consolidation and have positive effects on the CLQ.

Appropriate agricultural technical measures not only have important influences on the physical and chemical properties of the cultivated layer but also can reduce soil erosion and improve the CLQ. The questionnaire survey showed that the farmers participated in soil and water conservation at a rate of $31.4 \%$, which was mainly related to low crop production and low awareness of soil and water conservation. The implementation rate of improved tillage measures for deep ploughing was $81.4 \%$,which could improve the soil microbial environment [53], and the disturbance of the soil caused by this measure exceeded the depth of the cultivated layer involved in conventional tillage. This disturbance resulted in reduced soil bulk density of the lower part of the cultivated layer [54] and increased soil porosity [55], effective water performance of the bottom cultivated layer [56], and infiltration of soil moisture as well as soil water storage capacity [57]. Deep ploughing represented the main method for regulating the CLQ. The utilization rate of rotary tillers was $72 \%$, and the use of such agricultural machinery can greatly increase labour productivity. The implementation rate of crop rotation measures was relatively high at $72.2 \%$. A rational rotation of crops can effectively regulate 
soil moisture and increase the utilization efficiency of rainfall and soil moisture [58]; thus, it represented an important way to improve the resistance to seasonal drought. The implementation rate of ridge farming was slightly lower at a value of $46.2 \%$. Currently, ageing rural laborers and low labour efficiency represented the main reasons for the low implementation rate of this measure. Appropriate ridging has a better effect on preventing soil erosion, regulating runoff [59], improving the agricultural ecological environment and increasing the fertility of the soil of red soil sloping farmland than other cultivation methods.

\section{Conclusions}

Clear direct and reverse effects were observed among D, P, S, I and R, but the influencing path between $\mathrm{R}$ and I was not obvious. D was the fundamental driving force and potential incentive for causing cultivatedlayer degradation. During the variation in the CLQ, the contribution rates of $\mathrm{D}$ and $\mathrm{P}$ are all influenced by the comprehensive effects of natural and human factors. An increasing demand for agricultural modernization, improvements in agricultural mechanization, unreasonable farming and fertilization by farmers are all important factors that accelerate the cultivated-layer degradation of sloping farmland. The key indicators of $\mathrm{D}$ were annual rainfall and effective soil thickness, and the important indicators of $\mathrm{P}$ were the tillage methods. The cultivated-layer diagnostic indicator set included soil organic matter, total nitrogen, available potassium, soil bulk density, soil shear strength, soil texture, and $\mathrm{pH}$, which represent the production performance, the strength of the anti-erosion capacity, the tilth characteristic and the degree of acidification of the cultivated-layer. The CLQ of the lower slope is generally superior to that of the other slope positions. The positive response strategy (R) of sub-soiling plays an important role in suppressing, improving and preventing problems with CLQ.

\section{Acknowledgements}

This work was supported by the public welfare industry (agriculture) special research project (NO.201503119-01-01).

\section{Conflict of Interest}

The authors declare no conflict of interest.

\section{References}

1. CHEN S.F., CHEN X.Z., BAI Y.H., WANG L.Y. Evaluation of soil erosion vulnerability on the basis of exposure, sensitivity, and adaptive capacity: A case study in the Zhuxi watershed, Changting, Fujian Province, Southern China. Catena, 177, 57, 2019.

2. LI Y.Y. Study on the soil and water conservation via hedgerow in the slope Farmlands in Southern Hilly Region of China (Dissertation). Anhui Agricultural University, 2011 [In Chinese with English abstract].

3. WANG X.H., GAO Y.X., LI S.,MA W., LI Z.T. Research of evaluation indicator system of soil pollution prevention and control based on DPSIR concept model. Environ. Prot. Sci, 42 (4), 19, 2016 [In Chinese with English abstract].

4. LU Y.Z.Soil science.M.Chin. agric sci, 290-343, 2006 [In Chinese].

5. LI P., SHI K., WANG Y.Y., KONG D.N., LIU T., JIAO J.G., LIU M.Q., LI H.X., HU F. Soil quality assessment of wheat-maize cropping system with different productivities in China: Establishing a minimum data set. Soil Tillage Res. 190, 31, 2019

6. VERHULST N., GOVAERTS B., SAYRE K. D., DECKERS J., FRANCOIS M.I., DENDOOVEN L. Using NDVI and soil quality analysis to assess influence of agronomic management on within-plot spatial variability and factors limiting production. Plant Soil, 317 (1-2), 41, 2009.

7. OECD. OECD core set of indicators for environmental performance reviews. Environmental Monographs No. 83, Paris, 1993.

8. HOU Y., ZHOU S.D., BURKHARD, MULLER F. Socioeconomic influences on biodiversity, ecosystem services and human well-being: A quantitative application of the DPSIR model in Jiangsu, China. Sci. Total Environ. 490, 1012, 2019.

9. TIMMERMAN J.G., BEINAT E., TERMEER C.J.A.M., COFINO W.P. Developing transboundary river basin monitoring programmes using the DPSIR indicator framework. J.Environ. Monit, 13 (10), $2808,2011$.

10. SCHJØNNING P., AKKERer J.J.H.V.D, KELLER T. Driver-Pressure-State-Impact-Response (DPSIR) analysis and risk assessment for soil compaction - A European perspective. Adv. Agron, 133, 183, 2015.

11. LU W.W., XU C., WU J., CHENG S.P. Ecological effffect assessment based on the DPSIR model of a polluted urban river during restoration: A case study of the Nanfei River, China.Ecol. Indic. 96, 146, 2019.

12. ZHOU S.D., MUELLER F., BURKHARD B., CAO X.J., HOU Y. Assessing agricultural sustainable development based on the DPSIR Approach: Case study in Jiangsu, China. J. Integr. Agric, 12 (7), 1292, 2013.

13. BAE D.H., KOIKE T., AWAN J.A., LEE M.H., SOHN K. $\mathrm{H}$. Climate change impact assessment on water resources and susceptible zones identification in the asian monsoon region. Water Resour. Manag, 29 (14), 5377, 2015.

14. EISENHAUER N., BOWER M.A., GRACE J.B., POWELL J.R. From patterns to causal understanding: structural equation modeling (sem) in soil ecology. Pedobiologia, 58 (2-3), 65, 2015.

15. BOWKER M.A., EISENHAUER N., GRACE J.B. From patterns to causal understanding: Structural equation modeling (SEM) in soil ecology. Pedobiologia, 58 (2-3), 65, 2015.

16. BARDGETT R.D., VAN D.P, WIM H. Belowground biodiversity and ecosystem functioning. Nature, $\mathbf{5 1 5}$ (7528), 505, 2014.

17. MARCOS E.A., GERARD B.M.H. Including spatial correlation in structural equation modelling of soil properties.Spat. Stat. 25, 35, 2018. 
18. GAMA R.A.C., SALES B.M.V.S., SILVA B.P.S.D., COMERFORD B.N., CROPPER W.P., GAMA R.E.F. An exploratory analysis of phosphorus transformations in tropical soils using structural equation modeling. Biogeochemistry, 118 (1-3), 453, 2014.

19. RICHARD G.S., ADAM S.D., NICHOLAS R.Structural equation modeling facilitates transdisciplinary research on agtuculture and climate change. Crop Sci, 54, 475, 2014.

20. YANG R.M., GUO W.W., ZHENG J.B. Soil prediction for coastal wetlands following Spartina alterniflora invasion using Sentinel-1 imagery and structural equation modeling. Catena, 173, 465, 2019.

21. ZHAO P.Z., LI S., WANG E.H., CHEN X.X., DENG J.F., ZHAO Y.S. Tillage erosion and its effect on spatial variations of soil organic carbon in the black soil region of China.Soil Tillage Res, 178, 72, 2018.

22. MARTIN H.T., EGON B.N., MATHIEU L.A.F.L., CHRIS K.M.Z., PER S. Sustainable soil management - Farmers' perspectives on subsoil compaction and the opportunities and barriers for intervention. Land Use Pol, 86, 427, 2019.

23. HARGREAVESA P.R., BAKERB A., GRACESONC S., BONNETTD B.C., BALL J.M. Cloy.Soil compaction effffects on grassland silage yields and soil structure under different levels of compaction over three years. Eur. J. Agron, 109, 125916, 2019.

24. XIN Y., LIU G., XIE Y., GAO Y., LIU B.Y., SHEN B.Effects of soil conservation practices on soil losses from slope farmland in northeastern China using runoff plot data.Catena, 174, 417, 2019.

25. DURAISAMY V., SURENDRA K.S. Soil quality index (SQI) as a tool to evaluate crop productivity in semi-arid deccan plateau india. Geoderma, 282, 70,2016.

26. GUO L.L., SUN Z.G., OUYANG Z., HAN D.R., LI F.D. A comparison of soil quality evaluation methods for Fluvisol along the lower Yellow River. Catena. 152, 135, 2017.

27. RANJBAR A., EMAMI H., KHORASSANI R. Soil quality assessments in some iranian saffron fields. J. Agric. Sci. Technol. 18, 865, 2016.

28. SHABA H., EMAMI H.G., HAGHNIA H., KARIMI K.Pore size distribution as a soil physical quality index for agricultural and pasture soils in northeastern iran. Pedosphere, 23 (3), 312, 2013.

29. LI X.Y., WANG D.Y., REN Y.X., WANG Z.M., ZHOU Y.H. Soil quality assessment of croplands in the black soil zone of Jilin Province,China: Establishing a minimum data set model. Ecol. Indic, 107, 105251, 2019.

30. JIN H.F., SHI D.M., ZHONG Y.J., HUANG S.S., SONG G., DUAN T. Diagnosis of obstacle factors and degradation characteristics of cultivated-layer quality for red soil sloping farmland. Transactions of the CSAE, 35 (21), 84, 2019 [In Chinese with English abstract].

31. HUANG R.Z. Dynamic Change of Water Storage under Anti-Drought Measures on Red Soil Slope Farmland. Applied Mechanics \& Materials, 212-213, 564, 2012.

32. RANJBAR A., EMAMI H., KHORASANI R., KARIMI K.A.R .Soil quality assessments in some Iranian saffron fields. J. Agric. Sci. Technol, 18, 865,2016.

33. GUO Z., WANG D.Z. Long-term effects of returning wheat straw to croplands on soil compaction and nutrient availability under conventional tillage. Plant Soil Environ, 59 (6), 280, 2013.

34. FATEH B. Untangling the complexity of the direct and indirect determinants of the residential energy consumption in France: Quantitative analysis using a structural equation modeling approach. Energy Policy, 110, 246, 2017
35. NAIKUN K., DECHONG T., LI H.J., GOU Q.S., LI Q.Q., HAN H.F.,Effffects of subsoiling before winter wheat on water consumption characteristics and yield of summer maize on the North China Plain.Agric. Water Manage, 227, 105786, 2020.

36. YANG J., ZHENG H.J., CHEN X.A., SHEN L. Effects of tillage practices on nutrient loss and soybean growth in red-soil slope farmland. Int. Soil Water Conserv Res, 1 (3), 49, 2013.

37. MAYA K.A. Socioeconomic determinants of farmland value in India. Land Use Pol, 39, 78, 2014.

38. BRAUW D.A. Seasonal migration and agriculture in Vietnam. SSRN Electronic Journal, 4-7, 2007.

39. BRAUW D.A., ROZELLE S. Migration and household investment in rural China. China Econ. Rev, 19 (2), 320, 2008.

40. QUISUMBING A., MCNIVEN S. Moving forward, looking back: The impact of migration and remittances on assets, consumption and credit constraints in rural Philippines, Journal of Development Studies, 9, 1, 2010.

41. ZHAO Z.Y., LI W.C., ZHANG Y.Z., WANG, X. Evaluation on agricultural water and soil resources security in Ningxia based on DPSIR model. J. Acta Agric. Zhejiangensis, 29, 1336, 2017 [In Chinese with English abstract].

42. CAI Z., WANG B., XU M., ZHANG H., ZHANG L., GAO S. Nitrification and acidification from urea application in red soil (ferralic cambisol) after different long-term fertilization treatments. J. Soils Sediments, 14 (9), 1526, 2014.

43. LIU Z.P., SHI D.M., JIN H.F., LOU Y.B., LIN Z., YANG $X$.Soil quality and its limitation factors of slope farmland plough layer of red soil.Soil . Fertil Sci. China, 7, 13, 2018 [In Chinese with English abstract].

44. LIU X.B., ZHANG X.Y., WANG Y.X., SUI Y.Y., DING G. Soil degradation: a problem threatening the sustainable development of agriculture in northeast china. Plant Soil Environ, 56 (2), 87, 2010.

45. SUBEDI M., HOCKINGT.J., FULLEN M.A., MCREA A.R., MILNE E., MITCHELL D.J., WU B,Z. An Evaluation of the Introduction of Modified Cropping Practices in Yunnan Province, China, Using Surveys of Farmers' Households. Agricultural Sciences in China, 8 (2), 188, 2009.

46. ZHA Y., WU X.P., GONG F.F., XU M.G., ZHANG H.M., CHEN L.M., HUANG S.M., CAI D.X.Long-term organic and inorganic fertilizations enhanced basic soil productivity in a fluvo-aquic soil.J. Integr. Agric. 14 (12), 2477, 2015.

47. LIN C.W., TU S.H., HUANG J.J., CHEN Y.B. The effect of plant hedgerows on the spatial distribution of soil erosion and soil fertility on sloping farmland in the purplesoil area of China,Soil Till Res, 105 (2), 307, 2009.

48. ZHAO W.Z., XIAO H.L., LIU Z.M., LI J. Soil degradation and restoration as affected by land use change in the semiarid Bashang area, northern China.Catena, 59, 173, 2005.

49. MILLINGTON A.C., MUTISO S.K., KIRBY J., OKEEFE P. African soil erosion - nature undone and the limitations of technology. Land Degrad. Dev, 1 (4), 279, 2010.

50. AMELIE Q., JEROME B., JEAN P.G., CHRISTOPHE P. Soil degradation caused by a high-intensity rainfall event: Implications for medium-term soil sustainability in Burgundian vineyards.Catena 73, 89, 2008.

51. TANG W.J., LIU H.H., LIU B. Effects of gully erosion and gully filling on doil degradation in the black soil region of Northeast China. J Mt. Sci, 10 (5), 913, 2013. 
52. MANETA M.P., TORRES M.O., WALLENDER W.W. A spatially distributed hydroeconomic model to assess the effects of drought on land use, farm profits, and agricultural employment. Water Resour. Res. 45 (11), 179, 2009.

53. ANNKATHRIN G., GUIDO L., HERWART B., KNUT S., MELANIE W., MARKUS D.,ROBERT B., KLAUSPETER W., JURGEN H. Effect of ploughing depth and mechanical soil loading on soil physicalproperties, weed infestation, yield performance and grain quality insole and intercrops of pea and oat in organic farming. Soil Till Res, 148, 59, 2015.

54. MOSADDEGHI M.R., MAHOUBI A.A., SAFADOUST A. Short-term effects of tillage and manure on some soil physical properties and maize root growth in a sandy loam soil in western Iran.Soil Tillage.Res, 104, 173, 2009.

55. HAMILTON-MANNS M., ROSS C.W., HORNE D.J. Subsoil loosening does little to enhance the transition to no-tillage on a structurally degraded soil. Soil Till. Res, 68, 109, 2002.

56. MOTAVALLI P.P., STEVENS W.E., HARTWING G. Remediation of subsoil compaction and compaction effects on corn $\mathrm{N}$ availability by deep tillage and application of poultry manure in a sandy-textured soil. Soil Till. Res,71, 121, 2003.

57. JI B., ZHAO Y., MU X., LIU K., LI C. Effects of tillage on soil physical properties and root growth of maize in loam and clay in central China.Plant soil environ, 59, 295, 2013.

58. TUOMO P., HEIKKI L. Evaluating profitability of soilrenovation investments under crop rotation constraints in Finland.Agric. Syst, 180, 102762, 2020.

59. AN J., LIU Q.J., WU X.Y. Effect of Soil Wetting Rate on Hill slope Erosion Characteristics of Cinnamon Soil under Contour Ridge Cultivation.Transactions of the CSAM, 47 (10), 101, 2016 
